\title{
O ethos wikipedista como modo de combate à desinformação
}

\author{
The Wikipedian ethos as a way to fight misinformation
}

Pedro Rodrigues Costa ${ }^{a, *}$

\begin{abstract}
RESUMO: Este artigo debate a questão da neutralidade na produção e edição de verbetes na Wikipédia, bem como as proximidades existentes entre um ethos cientista e um ethos wikipedista. Durante esta discussão, lançam-se pistas para explicar o sucesso desta plataforma no combate à desinformação, às fake news e ao problema da pós-verdade. Discutem-se ainda as principais críticas e virtudes no que concerne à confiabilidade desta enciclopédia digital, refletindo depois sobre a importância de se pensar em modelos para se levar por diante o combate aos desafios da desinformação. No final, debate-se sobre a possibilidade de introdução de boas práticas wikipedistas nos processos de construção e difusão informativa e noticiosa, nomeadamente com a proposta de um regime noticioso colaborativo semiaberto.
\end{abstract}

Palavras-chave: Wikipédia; Pós-verdade; Desinformação; Fake News; Ethos Wikipedista.

ABSTRACT: This article discusses the issue of neutrality in the production and editing of entries in Wikipedia, as well as the proximity between a scientist ethos and a wikipedist ethos. During this discussion, clues are launched to explain the success of this platform in combating misinformation, fake news and the problem of the post-truth. We also discussed the main criticisms and virtues with regard to the reliability of this digital encyclopedia, reflecting later on the importance of thinking about models to carry out the fight against the challenges of disinformation. In the end, we discussed the possibility of introducing good wikipedist practices in the processes of construction and diffusion of information and news, namely with the proposal of a semi-open collaborative news regime.

Keywords: Wikipedia; Post-truth; Misinformation; Fake News; Wikipedist Ethos.

a Centro de Estudos de Comunicação e Sociedade, Instituto de Ciências Sociais, Universidade do Minho, Braga, Portugal.

*Correspondência para/Correspondence to: Pedro Rodrigues Costa. E-mail: pedrocosta@ics.uminho.pt.

Recebido em/Received: 25/02/2021; Aprovado em/Approved: 08/06/2021.

Artigo publicado em acesso aberto sob licença CC BY 4.0 Internacional $(9)$ 


\section{INTRODUÇÃO}

Duas décadas de vida e com a menção Vocể pela revista Time no currículo (Grossman, 2006), a Wikipédia é uma das plataformas mais visitadas no mundo (Alexa, 2021). Ao contrário de outros gigantes digitais, que visam fundamentalmente lucros e alimentam dinâmicas de promoção e marketing (Costa, 2020a; Costa, 2020b; Costa, 2020c), esta plataforma gerida coletivamente organiza-se em torno de uma fundação sem fins lucrativos de missão humanista: difundir livremente o conhecimento (Riese, 2013).

Assente nessa missão, a Wikipédia tem servido de exemplo na cooperação produtiva sem relações de mercado ou elaboradas estruturas hierárquicas. Apesar de algumas limitações e deceções, surge como âncora crítica para trabalhar alternativas ao neoliberalismo (Benkler, 2020). Uma das suas principais armas é a fusão das funções de ensino, investigação e serviço, desafiando a tradicional especialização e permitindo a passagem de uma posição tida como inimiga da docência para um agente capacitador do corpo docente (Cummings, 2020).

Tal evolução é percetível na cobertura mediática que obteve ao longo de duas décadas: tida inicialmente como uma frivolidade intelectual, é atualmente elogiada como um dos últimos bastióes da realidade partilhada (Benjakob \& Harrison, 2020). Tanto que hoje já se sugere uma colaboração permanente entre comunidades wikipedistas e jornalistas, no sentido de se aumentar a diversidade e a alfabetização digital devido aos resultados satisfatórios no combate às Fake News e à desinformação (Scofield, 2021; Preto, 2021; Carvalho, 2021).

Ainda assim, existem algumas desconfianças em torno da confiabilidade dos seus artigos, sobretudo na comunidade académica. As desconfianças podem ser agrupadas em três grandes grupos: i) ausência de hierarquias na produção; ii) ausência de validação por pares científicos; iii) inexistência de autor único ou de autoria individual de verbetes, limitando a responsabilização dos constructos informacionais (Miller, 2005; Jaschik, 2007; Esteves, 2012; Rabin, 2016). Estas críticas tendem a ser refutadas através da explicitação do próprio modo de produção colaborativo, que defende o uso de fontes de informação impressas e digitais, a permanente atualização de verbetes, o uso de fontes externas credíveis e a presença do princípio de imparcialidade, o que implica verbetes "elaborados de forma neutra e imparcial, abrangendo pontos de vista divergente sobre um mesmo assunto" (Braz \& Souza, 2014, p.25).

As novas plataformas de informação e comunicação funcionam, atualmente, como um conjunto de próteses de produção de emoções, isto é, como "maquinetas que modelam em nós uma sensibilidade puxada à manivela" (Martins, 2002, p. 182). Desta relação sociotécnica erguem-se sensibilidades e emoções que se subjetivam coletivamente e que se imitam (Costa, 2020a; Costa, 2020b), o que gera uma nova forma de estar, quer dizer, uma nova individuação social (Costa, 2020d; Neves \& Costa, 2020). Um aspeto central sobressai nesta nova individuação: as redes digitais,

\footnotetext{
${ }^{1}$ Esta menção aplica-se, de um modo geral, aos criadores de conteúdo na Internet. Os wikipedistas são parte desta comunidade.
} 
acionadas por intelectos algorítmicos que capturam a atenção dos sujeitos ao apelarem ao seu próprio ego, que é largado constantemente no algoritmo maquínico, vivem depois alimentadas por uma gritaria sócio-emocional (Costa, 2020a). É deste modo que as novas teletecnologias no geral, e as redes digitais em particular, apoiam a entrada das massas na história, reforçando o direito de se afirmarem enquanto sujeitos singulares. Todavia, o crescimento destas tecnologias de informação e comunicação tem sido quase sempre através dos sentidos auditivo e visual, assinalando assim um processo de translação de uma racionalidade do tipo argumentativo para uma racionalidade mais do tipo emocional, quer dizer, do logos e do ethos para o pathos, da ideologia para a sensologia (Perniola, 1993; Martins, 2011). E podemos acrescentar ainda Kairós, do grego kaıpóৎ, aquele que significa o momento oportuno, "certo" ou "supremo", isto é, a contingência feita momento onde se cruzam os interesses com as possibilidades que o momento confere, isto é, onde se formam os intelectos contingentes (Costa, 2020d).

Não obstante, e ao contrário de outros gigantes digitais como por exemplo o Facebook, o YouTube, o Twitter ou a Google, a Wikipédia vive alimentada maioritariamente pelo espírito não emocional, favorável ao logos e ao ethos, quer dizer, pelo cumprimento da palavra e de regras éticas. Não é que Kairós não lhe surja ou que não se faça sentir. Sabemos que as edições sobre personalidades ou acontecimentos na Wikipédia é tanto maior quanto maior é a relação entre o momento e a personagem ou o acontecimento - eis a força da contingência sobre os processos de produção Wiki (Costa, 2020d). Não obstante, é a palavra (o texto), e não a imagem, que comanda a ação ética e estética da Wikipédia. Misturando-se, é certo, questões de facto com questões de interesse (Latour, 2020), no que concerne à escolha de assunto para edição/ampliação de verbetes. O que, em certo sentido, vem na linha de pensamento de David Hume acerca do processo de produção e difusão de conhecimento: impressões, capturadas pelos sentidos, e ideias, que se desenvolvem a partir das impressões, permitem a deambulação entre factos e interesses do conhecimento (Grayling, 2020). A Wikipédia não escapa a esta dinâmica: tanto o acontecimento (questão de interesse mediático) como o assunto de especialidade temática (questão de facto) constituem fortes gatilhos da ação wikipedista.

Deste modo, a Wikipédia coloca, de modos diversos, vários desafios ao conhecimento e à legitimidade informacional. Primeiro porque é um dos recursos mais utilizados por estudantes, profissionais e até académicos (Bortolazzo \& Marcon, 2012). Depois porque é diabolizada por escolas e universidades, sobretudo devido ao excessivo uso em trabalhos escolares - o que por vezes gera proibições institucionais (Esteves, 2012, §27). Terceiro porque o seu modelo colaborativo e horizontal, acoplado a regras próprias de ação, conduta e citação, o seu livro de estilo rigoroso e um ethos próximo do cientista, como veremos adiante, dificultam a proliferação de campanhas individuais de publicidade, desinformação e fake news, o que indicia um conjunto de boas práticas a ter em conta (Costa, 2021b; Preto, 2021). 


\section{UMA NEUTRALIDADE AXIOLÓGICA NA WIKIPÉDIA?}

Antes de avançarmos para a discussão sobre os contributos da Wikipédia enquanto plataforma capaz de combater o problema da pós-verdade, da desinformação e das fake news, é necessário olhar para as fundações dos constructos científicos e das suas dinâmicas. É o caso das noções de objetividade, em contraposição com as de subjetividade, uma aspiração intelectual que na época de Max Weber e no campo do positivismo do século XIX significava a ideia de independência face aos valores e posições de um indivíduo diante de um objeto de estudo. A ideia de que o cientista seria capaz de se despojar completamente de valores e conceções pessoais, sem mediações e ideologias, preenchia o arquétipo de objetividade por essa altura.

Para tal se concretizar, por esta altura avançou-se com a ideia de uma ciência dos valores, designada de axiologia. A axiologia funcionaria como um barómetro da objetividade, que poderia vigiar a ciência e a sua difusão. Contudo, para Viana (2007) a axiologia enquanto "ciência dos valores é algo inexistente, não passa de uma proposta que nunca se realizou. Esta definição é marcada por uma inocência que releva seu caráter ideológico" (Viana, 2007, p.29). A crítica ao recurso a uma pretensa neutralidade axiológica e a um despojamento de valores que condicionasse a produção científica, colocaria o investigador dentro de contradições epistémicas, irremediavelmente ideológicas.

O que sobrou do esforço de pretensão de neutralidade axiológica foi sobretudo o afastamento de juízos de valores e a procura por maior imparcialidade, preconizado sobretudo por Max Weber (Mata, 2010). Ainda que para este a "objetividade" surja sempre entre aspas (Pereira, 2013), na perspetiva weberiana o procedimento científico deve ser realizado com o objetivo de apreender uma realidade concreta onde impere o máximo de neutralidade científica. Para isso, Weber propôs uma separação rigorosa entre os juízos de facto (o que é) e os juízos de valor (o que deve ser). Para Weber, o cientista deveria ficar pelos juízos de facto, na medida em que juízos de valor como crenças pessoais ou sentimentos, entre outros, não oferecem conhecimentos coerentes nem devem "ser extraídos de maneira nenhuma da análise científica, devido ao fato de derivarem de determinados ideais, e de por isso terem origens 'subjetivas"' (Weber, 2006, p. 109).

De acordo com Weber, o juízo de valor não cumpre o papel da ciência pois "uma das tarefas essenciais de qualquer ciência da vida cultural dos homens é a apresentação clara e transparente de suas ideias, para compreendê-las e para saber o porquê de se ter lutado por elas" (Weber, 2006, p.110). Considerando sub-repticiamente que o juízo está presente em todo o tipo de ciência, Weber chama a atenção para que se use a dimensão do juízo menos nefasta à imparcialidade científica, o que significa que tal implica delimitar o tema de investigação, cuidar das fontes de informação e precisar os métodos de recolha de mais informações para o constructo científico, ainda que estes sejam alvo de uma escolha individual e subjetiva. Por outras palavras, considerava praticamente impossível negar que uma investigação estivesse isenta de fatores 
históricos e contextuais subjetivos, ainda que o cientista devesse chegar a uma determinação o mais objetiva possível (Fonseca \& Braz, 1997, p.27). Por outras palavras, a ideia é a de que as perguntas de partida sejam de traço subjetivo, mas que o caminho para encontrar respostas seja livre de julgamentos ideológicos, tornando assim o processo o mais objetivo possível.

As questões da neutralidade e imparcialidade são muito caras à Wikipédia. Primeiro porque a imparcialidade surge como um dos cinco pilares fundacionais, nomeadamente o segundo pilar: "A Wikipédia rege-se pela imparcialidade" . No verbete correspondente a este pilar fundacional, intitulado de "Wikipédia: Princípio da imparcialidade" " é mencionado que "os artigos da Wikipédia devem ser imparciais, ou seja, devem ser escritos em uma forma com a qual ambos (ou todos) os lados envolvidos possam concordar com ele" ${ }^{3}$, devendo ser utilizado um PDVN (ponto de vista neutro).

A crítica à neutralidade axiológica da Wikipédia é a mesma que pode ser feita a Max Weber, ainda que existam diferenças: os cientistas, com formação em filosofia da ciência, são formados para efetuarem a distinção entre juízos de facto e juízos de valor, ao passo que os wikipedistas, muitos deles voluntários e com baixos níveis de formação em produção de ciência (Pequenino, 2021), podem conseguir escapar à comunidade colaborativa com o seu viés subjetivo, não tanto pela ausência de fontes, questão que é quase automaticamente detetada e encaminhada ou para correção ou para eliminação de verbete/edição, mas pelo modo menos treinado para fazer aquilo que Weber sugeria: ainda que as escolhas de fontes e temas sejam subjetivos, é fundamental encontrar um caminho para encontrar respostas livres de julgamentos ideológicos, tornando o processo o mais objetivo possível. Esta é, ainda que não formulada deste modo tão weberiano, uma das grandes críticas efetuadas à Wikipédia (Nunberg, 2007; McHenry, 2008; Numberg, 2009).

No entanto, para Braz \& Sousa (2014), estas críticas não têm razão de ser na medida em que o algoritmo sociotécnico, composto por humanos e não humanos (filtros, softwares, bots e scripts), permite verificação e atualizações constantes para fazer cumprir o princípio de imparcialidade. Isto é, uma espécie de mão invisível, voluntária, colaborativa e sociotécnica, corrige e aconselha alteração das edições sob pena de exclusão da contribuição. $O$ caso do filtro socio-semântico anti-vandalismo é disso um bom exemplo: qualquer tentativa de utilização de termos impróprios, como insultos, palavrões ou ameaças, é alvo de uma resposta quase imediata (Braz \& Sousa, 2014).

\footnotetext{
${ }^{2}$ Este pilar refere que "nenhum artigo deve defender um determinado ponto de vista. Por vezes torna-se necessária a apresentação dos diversos pontos de vista sobre um dado tema, o que deve ser feito de forma precisa e contextualizada. Implica igualmente justificar verbetes com fontes reputadas sempre que necessário, sobretudo em casos relacionados com temas controversos. Nenhum ponto de vista deve ser apresentado como o "verdadeiro" e/ou o "melhor", tampouco como o "falso" e/ou o "pior"”. Ver mais em https://pt.wikipedia.org/wiki/Wikip\%C3\%Agdia:Princ\%C3\%ADpio_da_imparcialidade.

3 Ver mais em

https://pt.wikipedia.org/wiki/Wikip\%C3\%Agdia:Princ\%C3\%ADpio_da_imparcialidade.
} 


\section{ACADEMIA VERSUS WIKIPÉDIA}

Partimos do princípio de que qualquer pessoa em geral, com um computador ou um smartphone e uma conexão à internet, acaba por usar, mais tarde ou mais cedo, a Wikipédia. Primeiro porque o modo como estão construídos os motores de busca em geral beneficiam o modelo da Wikipédia: tanto o PageRank da Google como os motores de busca do Bing ou da Yahoo oferecem, nas procuras semânticas de informação, uma dinâmica que se baseia em quatro fases: rastreamento, indexação, ordenação e utilidade. Esta lógica beneficia a Wikipédia, sobretudo nas dimensões de ordenação e utilidade (Casarotto, 2020, s.p.). Depois porque existem sempre perguntas de âmbito estrito de aprendizagem e ensino, sobretudo nas dinâmicas complementares da informação, como conceitos, palavras ou termos, que estão fora dos sistemas de ensino, mas dentro do largo espectro de conhecimentos necessários à aprendizagem em geral (Jemielniak, 2020).

Mas não só de ordenação de dados, utilidade e complementaridade vive a Wikipédia. Alguns estudos têm demonstrado que a precisão da Wikipédia está ao nível das enciclopédias "profissionais", ainda que existam preconceitos de ambos os lados da produção e difusão de conhecimento (Giles, 2005; James, 2016; Greenstein \& Zhu, 2018).

Para Jemielniak (2020), não há muitas razões de ser das desconfianças em relação a esta enciclopédia digital por parte da academia, uma vez que são três as vantagens da escrita ou edição de verbetes no seu ecossistema: 1) mesmo que o verbete escrito esteja pouco desenvolvido, será sempre de utilidade para muitos leitores, que também podem melhorá-lo gradualmente e ajudá-lo a crescer. Permite deste modo uma retribuição à sociedade, recompensando-lhe o esforço de formação de pessoas, bem como o apoio aos menos privilegiados em que em muitos casos esta enciclopédia digital funciona como a única ou a principal fonte de conhecimentos; 2) a escrita de um verbete enciclopédico, ou a edição de algo já existente, é um esforço tipicamente académico na medida em que requer uma coleção de referências válidas e confiáveis, forte capacidade de síntese e de precisão e capacidade de escrever de uma maneira axiologicamente neutra. Além disso, o facto de se saber lido por grandes camadas populacionais aumenta consideravelmente o nível motivacional; 3) aquilo que é escrito na Wikipédia, seja de raiz ou de edição complementar a verbetes já existentes, é imediatamente verificado quanto a plágio, quanto a ausência de referências externas e quanto a frases mal escritas. A comunidade colaborativa é suficientemente "aborrecida" nesse sentido (Jemielniak, 2020).

Ainda assim, estas três virtudes não são suficientes para convencer a academia. Jemielniak (2020) justifica esse não convencimento por quatro ordens de razão: 1) editar na plataforma da Wikipédia é, nas primeiras vezes, difícil. Há um grande número de regras de edição e formatação que devem ser seguidas, e qualquer professor que incluísse a escrita da Wikipédia no seu currículo também teria que dominá-las, mesmo que apenas para ser capaz de responder a perguntas simples; 2) a Wikipedia é representada pela academia como algo de impreciso. Não importa se a confiabilidade 
seja tida como alta, de acordo com estudos académicos publicados, nem que seja representada pelos média como uma fonte neutra de informação ou que a maioria dos estudantes de medicina a considere útil e a use para aprender com bons resultados. A perceção geral está moldada mais por erros e casos espetaculares e mediáticos do que o seu contrário, sobretudo no universo digital. 3) existe, atualmente, uma grande crise de confiança na ciência, levando a um crescendo de reações defensivas e de rejeição por parte da academia. Comunidades de "alterscience", negacionistas, antivaxxers ou terra planistas produzem um ecossistema crescente de anti-intelectualismo. Associadas a notícias falsas e a propagandas em rede, um dos efeitos colaterais evidentes é o rápido declínio da autoridade da ciência no público em geral. A par disso, sistemas de busca de informação como a Google tornaram-se em autoridades junto dos que procuram informações, o que faz com que os não especialistas tenham cada vez menos respeito pela autoridade académica formal. Em certo sentido, a ameaça da Wikipédia reside nesta bifurcação: há um forte crescimento de uma ciência cidadã, movimento global de amadores e voluntários que recolhem e interpretam dados, às vezes produzindo descobertas científicas válidas. Contudo, ainda que se vise a difusão e democratização do conhecimento científico, usando até regras em parte semelhantes às da academia, não se tem alterado muito a representação social sobre a Wikipédia e os wikipedistas. Juízos de valor negativos recaem sobre a Wikipédia e sobre a possibilidade de se estar a impor um modelo anti-credencialista e antiespecialista. 4) finalmente, o facto da gestão da Wikipédia parecer bizarra e caótica, sendo muitas vezes confusa. Além disso, por princípio aparenta ser não hierárquica o que não é verdade. Para os professores em geral, sem dúvida uma das profissões tradicionalmente mais estruturadas, esta ideia de caos e de ausência de liderança surge como um pesadelo (Jemielniak, 2020; Esteves, 2012; Pestana, 2018).

Por outro lado, Nora Miller (2005) considera que com a Internet em geral, e com a Wikipédia em particular, terá havido um retorno a um tempo onde se dá o “desaparecimento do autor". No caso concreto do modo de produção de informação wikipedista, isso deve-se precisamente a uma "cultura de produção e escrita colaborativa" (Miller, 2005, p. 39). Nada disto é original, se pensarmos que na Antiguidade Clássica o comum era que os escritos fossem produzidos a várias mãos (Grayling, 2020). No entanto, Miller (2005) considera que esta cultura contraria a cultura legal em torno dos direitos autorais, provocando o sistema instituído ao colocar pessoas em torno da "ideia de que cada leitor pode adicionar, alterar ou mesmo apagar outros documentos escritos", deixando com isso alguns escritores/editores pouco confortáveis (Miller, 2005, p. 39).

Miller faz uma comparação significativa: "Assim como Newton reconheceu que se apoiou nos ombros de gigantes, também os autores wiki entendem que a gravação de informações por qualquer um de nós realmente só se baseia nos esforços de todos os outros pensadores, leitores e escritores que já existiram" (Miller, 2005, p. 39). Este modo "abraça o processo natural da leitura e da escrita, preferindo o "produto" em constante evolução, mas nunca terminando, ao "produto" estático e rapidamente obsoleto" (Miller, 2005, p. 39). No seu entender, isto não se trata de anonimato na sua totalidade pois o que está em causa no processo colaborativo e reticular não é tanto o 
anonimato, mas antes a diluição do autor. E é aqui que pode residir uma grande questão: mesmo os registos que a Wikipédia grava em cada alteração, não tem como objetivo a autoria, mas antes o registo, quer dizer, "se uma página mudou desde a última vez que a visualizaram ou para descobrir a identidade de um escritor que talvez introduziu um erro ou um comentário espúrio" (Miller, 2005, p. 40).

Combinadas, todas estas questões geram uma guerra de mundos com visões diferentes nos processos de produção: academia e Wikipédia. Isto revela, em nosso entender, uma luta muito concreta pelo poder e pela hegemonia do conhecimento. A Wikipédia ocupa, de facto, um nicho anteriormente reservado àqueles que se situam no topo da hierarquia académica (Esteves, 2012). Trata-se, em nosso entender, daquilo a que Pierre Bourdieu (1989) chamou de uma luta pelo "poder simbólico", um poder capaz de

constituir o dado pela enunciação, de fazer ver e fazer crer, de confirmar ou de transformar a visão do mundo e, deste modo, a seção sobre o mundo, portanto o mundo; poder quase mágico que permite obter o equivalente daquilo que é obtido pela força (física ou econômica), graças ao efeito específico de mobilização, só se exerce se for reconhecido, quer dizer, ignorado como arbitrário. Isto significa que o poder simbólico reside nos «sistemas simbólicos» em forma de uma «illocutionary force» mas que se define numa relação determinada - e por meio desta - entre os que exercem o poder e os que lhe estão sujeitos, quer dizer, isto é, na própria estrutura do campo em que se produz e se reproduz a crença (Bourdieu, 1989, p. 15).

De facto, os sistemas simbólicos - produtos e produtores de estilos de vida e de crenças sociais - detém uma relação inseparável com sistemas de poder, funcionando como "instrumentos de imposição ou de legitimação da dominação, que contribuem para assegurar a dominação de uma classe sobre a outra (violência simbólica)" (Bourdieu, 1989, p.11).

Eis então que surge um paradoxo: se a Wikipedia é tão amplamente popular e eficaz na disseminação de conhecimento, os estudiosos, sobretudo académicos, não deveriam desenvolvê-la avidamente? A resposta a este paradoxo é a de que a Wikipédia apresenta como grande metáfora de fundo a ideia de jogo, o que ameaça radicalmente a academia. Para Jemielniak (2020), a Wikipedia é um jogo de RPG. É um RPG multiplayer online amplamente popular (MMORPG). Dito de outra forma, trata-se de um experimento massivo de investigação-ação colaborativa (Hill \& Shaw, 2020), que interage na criação de um movimento social de construção de conhecimento dividido entre a colaboração de boa-fé (partindo do princípio de que a má-fé é considerada vandalismo e automaticamente eliminada), comportamentos pró-sociais e as inevitáveis lutas políticas, tensões e reflexos de preconceitos sociais (Reagle, 2010; Tkacz, 2015; Rijshouwer, 2019).

Para Jemielniak (2020), os participantes do RPG-Wikipedia desempenham o papel de escritores de enciclopédia. Independentemente da idade ou ocupação, tendem a levar muito a sério a questão de permanecer nessa personagem. Criaram uma infinidade de regras sobre como colocar o ego de lado no que concerne a propriedade autoral fixa, 
ou sobre como se comportar em trabalho colaborativo ${ }^{4}$. O número de políticas e diretrizes comportamentais na Wikipédia é hoje muito maior do que na maioria das organizações profissionais, na medida em que existem "quarenta e cinco mil palavras apenas sobre a conduta adequada, e há mais de mil outros documentos regulamentares sobre outros aspetos da Edição da Wikipedia, com uma contagem de palavras atingindo milhões no total" (Jemielniak, 2020, p. 21).

Ainda que seja "diabolizada devido ao excessivo uso em trabalhos escolares, gerando até a proibição de utilização em escolas e universidades" (Esteves, 2012, p. 27), as críticas tendem a ser refutadas por estudiosos que defendem que "a produção colaborativa de conteúdos na Wikipédia está relacionada a indicadores de confiabilidade que convergem elementos de fontes de informações impressas e digitais" (Braz \& Sousa, 2014, p. 9). Além disso, é evocado como defesa o facto de os verbetes estarem "constantemente sendo atualizados, o que é providencial para a confiabilidade das informações" (Braz \& Souza, 2014, p.9), e que o princípio da imparcialidade que existe no seio da Wikipédia implica "que os artigos e verbetes sejam elaborados de forma neutra e imparcial, abrangendo pontos de vista divergente sobre um mesmo assunto" (Braz \& Souza, 2014, p.25).

Ao princípio da imparcialidade que o sistema implica, somam-se o princípio de notoriedade, no que toca a acontecimentos e biografias, e o princípio de "Nada de Pesquisa Inédita, Fontes Primárias e Direitos Autorais. Eles mantêm uma interligação, pois asseveram que os artigos produzidos colaborativamente devem ter como referências outras fontes de informação, conhecidas e reputadas" (Braz \& Souza, 2014, p.25).

Ainda assim, a atual convergência de meios (Jenkins, 2008) que ocorre na Wikipédia implica uma vigilância constante, pois a credibilidade e a legitimidade dos meios de informação, particularmente daqueles que se inscrevem na lógica do instantâneo e que estão em permanente regime colaborativo estão sujeitos à contingência dos factos, à quantidade de editores envolvidos nos processos de produção de verbetes e ao modo como os editores envolvidos idealizam o mundo e o conhecimento (Kiousis, 2009; Costa, 2021a; Dondio, Barrett, Weber \& Seigneur; 2006). Não é possível remeter a questão da confiança na Wikipédia apenas para as fontes externas citadas (Sundin, 2011).

\section{UM ETHOS DECALCADO DO CIENTISTA}

Tal como refletia Max Weber sobre as questões da neutralidade, todo o processo científico beneficiou da reflexão crítica sobre o positivismo. E nisso não foi alheio o processo de construção enciclopédico tradicional. Importa por isso questionar sobre os pontos de contacto entre os processos tradicionais de construção de uma

\footnotetext{
${ }^{4}$ Ver, a este respeito, as normas do livro de estilo e as normas de conduta em: https://pt.wikipedia.org/wiki/Wikip\%C3\%Agdia:Livro_de_estilo e https://pt.wikipedia.org/wiki/Wikip\%C3\%Agdia:Normas_de_conduta.
} 
enciclopédia e os processos de construção sociotécnica desta enciclopédia digital. A questão é: será a estrutura organizacional wikipedista o resultado de um recalcamento do ethos científico, proveniente sobretudo dos séculos XIX e XX?

Partindo da teoria das imitações, proposta no já longínquo final do século XIX por Gabriel Tarde (1978), a ação social parte do complexo para o simples, na medida em que primeiro se dão processos psicossociológicos complexos de imitação e conexão, e só depois estes variam para movimentos que tendem para a expansão e universalização simplificada do gesto, das opiniões, dos modos e das ideias. Dentro desta tese, a imitação é o lado objetivo que demonstra o sentido da expansão e universalização das forças subjetivas, e a contra-imitação é resposta seguinte à imitação, que parte da mesma força inicial, mas subtraindo-lhe com um sentido oposto. Por seu turno, quando nem imitação nem contra-imitação são consideradas suficientes pelos sujeitos, eis que a invenção surge como uma derivação da força inicial - nem a favor nem contra, necessariamente. Antes origina uma nova linha de fuga em que nascem possibilidades novas e diferentes forças. Depois da invenção, um novo ciclo imitativo inicia (Tarde, 1978).

Partindo desta premissa, podemos considerar a Wikipédia como um produto resultante da potencia inicial, acontecida agora num encontro entre pessoas que utilizam o digital como modo de executar uma contra-imitação ao modelo das enciclopédias tradicionais. Estas vivem povoadas pelo ethos científico, na medida em que na sua maioria foram cientistas e divulgadores de ciência que iniciaram a sua dinâmica. Todavia, no caso da Wikipédia, convergem tecnologias contingentes que permitem uma transcriação sociotécnica, criação de conteúdos de conhecimento e respetivas difusões universais (internet, colaboração reticular digital, scripts, bots, etc.). O seu modelo organizacional envolve-se em torno de várias possibilidades imitativas, noutros ciclos, apropriando-se das possibilidades que o modelo colaborativo e reticular permite e que por si só compõe um tipo novo de cultura.

Dentro desta lógica voluntária, colaborativa e reticular, o editor wikipedista repesca, então, em nosso entender, o ethos que Robert King Merton (1973) atribuía ao cientista. Devido aos cinco pilares fundacionais, a um conjunto alargado de regras e a normas de conduta próprias, tanto wikipedistas como cientistas partilham quatro processos similares: universalismo, comunismo, desinteresse e ceticismo organizado.

No que concerne à relação do wikipedista com o universalismo, e em semelhança com o cientista na perspetiva mertoniana, esse está sujeito a um padrão universal de regras provenientes do ecossistema próprio da Wikipédia. Ainda que aqui o universal signifique o todo em determinado idioma. De facto, as suas entradas, edições ou investigações nesta enciclopédia digital seguem, quase obrigatoriamente, padrões universais de avaliação da respetiva cultura organizacional idiomática.

Já no que concerne à dimensão comunista invocada por Merton (1973), tanto no cientista como no wikipedista esta aproxima-se na medida em que o conhecimento, proporcionado pelo trabalho de realização, aprovação e manutenção de uma entrada no seu ecossistema constitui património comum da humanidade, e não tanto uma 
propriedade privada - ainda que possa ser usada posteriormente para uma base de um produto comercial. Mesmo que se trate de uma biografia aparentemente definitiva, essa pode ser contestada, modificada, ampliada e sempre melhorada por wikipedistas que descobrem novos dados ou que conhecem novas histórias acerca do biografado 5 .

Por seu turno, a dimensão do desinteresse relaciona-se com os fins a que está destinada. A Wikipédia, enquanto organização sem fins lucrativos, encontra na reprodução de conhecimentos e na sua verificação e validação um objetivo maior, que é o da ampliação universal do acesso a conhecimentos e saberes. Neste sentido, o ethos do wikipedista também se aproxima do cientista, que é, num curto espaço de tempo, o da ampliação e da propagação do conhecimento (Merton, 1973).

Finalmente, o quarto e último aspeto do ethos wikipedista, que acaba por ser forçado pelas regras universais do ecossistema da Wikipédia, é a obrigatoriedade de utilização e de cruzamento de fontes independentes, com validade ou legitimidade científicas. Esta premissa conduz inevitavelmente o wikipedista a um certo ceticismo organizado, privando-o de formas de preconceito e de conclusões precipitadas sobre as entradas a criar. Está, pois, de acordo com a dimensão do ceticismo organizado atribuído por Merton (1973) ao cientista.

Toda esta analogia com o ethos científico está plasmada, ainda que por outras palavras, nos cinco pilares fundadores da Wikipédia, escritos aquando da sua apresentação. A saber:

A Wikipédia é uma enciclopédia de amplo escopo que compreende elementos de enciclopédias generalistas, de enciclopédias especializadas e de almanaques. A Wikipédia não é um repositório de informação indiscriminada. A Wikipédia não é um dicionário, não é uma página onde se coloca o currículo, um fórum de discussão, um diretório de ligações ou uma experiência política. A Wikipédia não é local apropriado para inserir opiniões, teorias ou experiências pessoais. Todos os editores da Wikipédia devem seguir as políticas que não permitem a pesquisa inédita e procurar ser o mais rigorosos possível nas informações que inserem.

A Wikipédia rege-se pela imparcialidade, o que implica que nenhum artigo deve defender um determinado ponto de vista. Por vezes torna-se necessária a apresentação dos diversos pontos de vista sobre um dado tema, o que deve ser feito de forma precisa e contextualizada. Implica igualmente justificar verbetes com fontes reputadas sempre que necessário, sobretudo em casos relacionados com temas controversos. Nenhum ponto de vista deve ser apresentado como o "verdadeiro" e/ou o "melhor", tampouco como o "falso" e/ou o "pior".

A Wikipédia é uma enciclopédia de conteúdo livre que qualquer pessoa pode editar. Todos os textos estão disponíveis nos termos da Atribuição-Compartilhamento pela

\footnotetext{
${ }^{5}$ Ainda assim, a questão do termo "comunismo" deve ser usada como princípio de património comum, e não tanto pela perspetiva da propriedade privada, o que exige cautela com esta terminologia. As licenças usadas pela Wikipédia, nomeadamente a licença CC BY-SA 3.0, implicam três modos de olhar para o que na plataforma da Wikipédia: é possível a partilha a partir da cópia, da redistribuição do material em qualquer suporte ou formato e a adaptação no sentido de remistura, transformação e criação a partir do material para qualquer fim, ainda que comercial.
} 
mesma Licença 3.0 Unported (CC-BY-SA 3.0), mas grande parte do conteúdo também está disponível sob GNU Free Documentation License (GFDL). Estas licenças autorizam qualquer um a criar, copiar, modificar e distribuir o conteúdo da Wikipédia, à condição de conservar esta mesma licença em usos posteriores, assim como creditar os autores originais. As suas contribuições também não devem violar nenhum direito autoral (copyright), nem serem incompatíveis com o licenciamento da Wikipédia. Como nenhum artigo possui dono e ninguém tem o controle de um artigo em particular, todo o conteúdo inserido na Wikipédia pode ser modificado e redistribuído sem aviso prévio por qualquer pessoa, inclusive de forma comercial.

A Wikipédia possui normas de conduta. Respeite os outros editores da Wikipédia, mesmo que não esteja de acordo com eles. Comporte-se de forma civilizada, evite fazer ataques pessoais e generalizações. Mantenha-se calmo durante as disputas, procure 0 consenso e evite guerras de edições. Recorde que a Wikipédia lusófona possui 1047 787 artigos nos quais você pode trabalhar. Sobretudo, assuma a boa-fé. Não utilize contas múltiplas para apoiar determinadas posições, insultar ou para participar de quaisquer tipos de votações.

A Wikipédia não possui regras fixas, além dos cinco princípios gerais elencados nesta página. Seja audaz ao editar os artigos, pois a satisfação de editar reside em não ser necessário alcançar a perfeição na primeira vez. E não se iniba de editar por temer colocar as coisas de pernas para o ar. Todas as versões dos artigos são preservadas num histórico, de modo que não é possível danificar definitivamente a Wikipédia ou destruir irremediavelmente a informação ${ }^{6}$.

No entender de Vogt (2003), a cultura científica, e o respetivo ethos, é constituída pelo conjunto de ações humanas nos processos sociais de produção, difusão, ensino e divulgação do conhecimento científico. Para Padilha, Lima Júnior \& Santos (2019, p.7), a Wikipédia vai até mais longe na medida em que através dos atuais esquemas sociotécnicos "apresenta uma espiral constante que se retroalimenta, o que acaba por dialogar com a espiral da cultura científica".

Dentro desta perspetiva, são quatro os quadrantes na espiral da cultura científica, nomeadamente: produção e difusão da ciência, ensino da ciência e a formação de cientistas, ensino para a ciência e, finalmente, divulgação científica (Vogt, 2003). Ora, de certo modo estes quatro quadrantes ficaram inscritos nos esquemas imitativos dos primeiros wikipedistas, o que depois acaba por fortalecer os argumentos da Wikimedia Movement, que pretende "apoiar o conteúdo sob o conceito de conteúdo livre e aberto. A Wikipédia é o produto mais famoso do movimento Wikimedia"7.

\section{UMA MISSÃO E UM ETHOS QUE ATACAM OS PRESSUPOSTOS DA DESINFORMAÇÃO}

Para Antoni Bassas (2016), o neologismo "pós-verdade" refere-se a todas as situações em que se verifica que factos objetivos comportam menos influência do que apelos às emoções e crenças pessoais. Para Bruno Latour (2020), esta postura de pós-verdade é

\footnotetext{
${ }^{6}$ Ver mais em https://pt.wikipedia.org/wiki/Wikip\%C3\%A9dia:Cinco_pilares.

7 Ver mais em

https://m.wikidata.org/wiki/Help:Wikimedia?fbclid=IwARo8y7ZgioOLOaYUs3ZSxDBhLerixzEnV Ho7BN2CHligugsoLc9_5POi_Ks
} 
uma atitude de defesa, na medida em que preconiza a ideia "de que existem verdades alternativas que o sujeito pode escolher". O que, no seu entender, é muito diferente do modo de construir ciência baseado num "ceticismo racional” (Latour, 2020, p. 11). Esta atitude vai contra os princípios da ciência, contra a neutralidade axiológica descrita anteriormente e, tal como já vimos, contra os próprios pilares éticos da Wikipédia - daí estar a sofrer fortes resistências por parte da comunidade wikipedista.

O conceito de pós-verdade relaciona-se com o conceito de fake news, na medida em que estas consistem em informação distribuída em canais de informação tendo como objetivo deliberado a desinformação ou o boato com a intenção de enganar para obtenção de ganhos, financeiros ou políticos. As fake news apelam também a emoções que se pretendem manipular, muitas vezes apoiadas em títulos sensacionalistas, exagerados ou evidentemente falsos para chamar a atenção (Hunt, 2016).

A problemática da pós-verdade e das fake news relaciona-se com a era do ecrã de um modo simultaneamente complexo e subtil. Neste pretende-se sobretudo "chamar a atenção", sugerir o "dar vistas". O ecrã funciona como um palco, onde se "chama a atenção do outro" (Costa, 2020c). Porém, no palco do ecrã o período da atenção é curto. Ao vivermos naquilo a que Bruno Patino (2019) apelidou de "civilização do peixevermelho" (para se referir ao curto período de atenção dos mais jovens), civilização marcada pela omnipresença de sujeitos mediados por smartphones, somos comandados por uma economia digital produtora de técnicas de "captologia" (ciência da captura da atenção) onde convergem diversos meios sociotécnicos e da psicologia comportamental (Jenkins, 2009), ficando reféns de vários tipos de estratégias de captura da atenção. As grandes empresas digitais sabem que a atenção é o seu alvo e, nesse breve intervalo capaz de atrair o olhar, toda uma economia se desenvolve economia da atenção. Por isso é que as fake news se tornaram a "lança" da pósverdade, exponenciando-a (Patino, 2019). Os factos, ainda que vagamente empíricos e vagamente corretos, são "fornecidos por milhares de fazendas de notícias falsas na Sibéria" (Latour, 2020, p. 11), colocando a contingência sociotécnica sob o efeito de um misto de informações subjetivas, escolhas racionais e relações emocionais para com os assuntos, desarmando os sujeitos.

É aqui que os princípios de neutralidade e imparcialidade da comunidade wikipedista entram. De acordo com as regras que esta comunidade tende a fazer cumprir, questões de interesse do wikipedista terão que se cruzar com questões de facto através de fontes externas e imparciais, sob pena de o verbete ser imediatamente excluído pela comunidade. Além disso, é incentivado o contraditório, ainda que a visão seja extremamente minoritária. A esse respeito, nas regras da imparcialidade (Wikipédia: Princípio da imparcialidade), na secção "Proporção em função dos pontos de vista”, pode ler-se sobre a importância das visões minoritárias o seguinte:

Por exemplo, o artigo sobre a Terra não menciona teorias modernas que defendem que a Terra seja plana, um ponto de vista extremamente minoritário. Em artigos especificamente sobre pontos de vista minoritários, é permitido que tais visões recebam mais atenção e espaço, porém, em tais páginas, embora o ponto de vista minoritário pode (e normalmente deve) ser descrito, 
possivelmente de forma mais detalhada, o artigo deve fazer referência adequada para a visão majoritária sempre que pertinente, e não deve refletir uma tentativa de reescrever os conteúdos da visão majoritária estritamente sob a perspectiva da visão minoritária ${ }^{8}$.

Quer isto dizer que o confronto entre visões maioritárias e visões minoritárias é fortemente incentivado, ainda que ambas as visões devam ter uma separação clara e sem a tentativa de reescrita de ambos os pesos. A perspetiva da Wikipédia é a da neutralidade para com os diferentes pesos sociais existentes, evitando interferências nessa proporcionalidade. Ou seja, há aqui a manutenção daquilo que é tido como maioritário na ciência em geral, aliviando o ecossistema wikipedista de decisão já que é "estrondoso o número de coisas que o indivíduo precisa de saber para decidir o que é factual e o que não é" (Latour, 2020, p. 12). Em As controvérsias da ciência na wikipédia em português:

o caso do aquecimento global, Bernardo Costa revela que a Wikipédia tende a expor a visão mais consensual da ciência do clima, ainda que abrigue também espaços marginais em que os argumentos dos céticos resistem. De acordo com as suas conclusões, a Wikipédia age como um porta-voz da ciência, renovando o enciclopedismo moderno ainda que esteja pouco aberta a outras formas de conhecimento (Costa, 2014).

Numa perspetiva mais crítica, digamos que a Wikipédia transfere a responsabilidade para as visões maioritárias assentes em ciência e fontes credíveis de acordo com os cânones científicos vigentes, o que não significa total isenção - de resto, o mesmo acontece com a ciência em geral, na medida em que o problema da pós-verdade expõe um problema mais vasto, que é o do "capitalismo da informação" (Castells, 2007). O capitalismo informacional deixa de ter a ver com produção em massa para passar a ser uma espécie de capitalismo de vigilância, quer dizer, em vez de operários explorados temos milhões de humanos nas redes e também nas comunidades colaborativas aproveitados para veicular mercadorias (Neves, 2020a). Aqui as mercadorias são constituídas por informações que pretendem capturar novos imitadores e propagadores para intenções mais profundas (modelos de governação, ideais políticoeconómicos, interesses corporativistas, etc.). A este respeito, conclui-se que o principal "ator" do capitalismo da informação é a "economia da atenção", e a "captologia" aparece como a técnica preferida da contingência sociotécnica para efetuar a associação entre a informação a veicular e o agente transmissor, superando em eficácia os restantes agentes primários de informação, inclusive ciência e escola (Patino, 2019; Costa, 2020c). Neste ponto, também à Wikipédia fica difícil resistir, ainda que indiretamente.

Para contrariar esta onda do capitalismo informacional, entram os argumentos universalistas e antiliberalistas da Wikipédia (Benkler, 2020). Uma missão sem fins lucrativos, um ethos decalcado do cientista, uma postura pouco hierárquica na produção e um conjunto de regras, normas e processos sociotécnicos próprios,

\footnotetext{
${ }^{8}$ Citação retirada de https://pt.wikipedia.org/wiki/Wikip\%C3\%Agdia:Princ\%C3\%ADpio_da_imparcialidade.
} 
concretizam continuamente uma cultura própria, que pode ser resumida em seis pontos fundamentais, diminuindo no seu ecossistema o poder e a presença da pósverdade, das fake news e da desinformação. De modo resumido: i) o facto de a Wikipédia funcionar como fundação sem fins lucrativos. Logo, não vive para o lucro e por isso não convive com a necessidade de receitas oriundas de publicidade, Marketing e propaganda. Pelo contrário, gigantes digitais como o Facebook, o Twitter ou o YouTube têm como foco o lucro; ii) um objetivo geral que visa uma difusão universal de conhecimento e não uma angariação universal de pessoas para ficar na sua rede. Quem pretende fazer difusão universal de informação no seu ecossistema tem que cumprir as suas regras e normas de conduta; iii) a Wikipédia não é, na sua estrutura orgânica, uma rede digital típica. Trata-se, antes, de uma comunidade digital colaborativa. Partindo da distinção de Bauman (Apud Querol, 2016) entre rede digital e comunidade digital, numa rede o sujeito organiza um conjunto de pessoas e grupos com quem se quer relacionar. Pode ligar-se e desligar-se, acrescentar ou eliminar pessoas arbitrariamente. Habitualmente, este tipo de redes é atravessado pela semelhança e pelo idêntico (Han, 2018). Pelo contrário, numa comunidade é necessária uma relação com um todo diverso, com vários grupos diferentes, em que há necessidades de negociação permanentes. É o que acontece nos processos de produção na Wikipédia: para se criar ou editar algo é necessário cumprir regras comunitárias, negociar processos, respeitar contributos e conselhos dos que estão no sistema há mais tempo. Nem sempre acontece, mas é esta norma; iv) a Wikipédia não é gerida de cima para baixo (modo top-down), ainda que exista hierarquização de funções, mas antes em consenso de maiorias e até mesmo através de sistemas de votação. Ao ser gerida assim não obedece tanto a ímpetos arbitrários, habitualmente implícitos nos princípios inscritos na ideia de lucro (competição, propriedade, maisvalia, etc.). O objetivo é o do consenso em torno de regras de ação no seu interior e o da garantia de fontes confiáveis; v) um ethos semelhante ao do cientista implica um modo de estar que escapa às forças do capitalismo informacional. Universalismo, comunismo, desinteresse e ceticismo organizado (Merton, 1973) estão em planos antagónicos aos desse capitalismo informacional; vi) finalmente, o algoritmo da Wikipédia é a própria comunidade humana de editores/criadores, ainda que acompanhada por filtros, softwares, bots e scripts como recursos de manutenção, organização e gestão da informação. Ao contrário do que acontece noutras plataformas digitais, não existe na Wikipédia um algoritmo com apetência de captura de atenção nem de retenção na rede. É a aceitação e o cumprimento das regras da Wikipédia por parte da comunidade colaborativa que coloca os verbetes da Wikipédia no topo dos motores de busca, e não um sistema de anúncio-patrocinado como acontece noutras plataformas 9 .

\footnotetext{
${ }^{9}$ A este respeito, Katherine Maher, presidente executiva da Fundação Wikimedia, refere que o sistema da Wikipédia é mais eficiente no combate às fake news do que o das plataformas de seleção de conteúdo por algoritmos ou dos aplicativos de mensagens porque não tenta "manter você no site o máximo de tempo possível, não mostramos a você conteúdo gerado por algoritmo. O que tentamos fazer é ter certeza de que você tenha a informação de que precisa e que ela seja o mais precisa possível. Acho que há muito na Wikipédia que outras
} 


\section{CONSIDERAÇÕES FINAIS}

Não assente em regras de mercado, onde as pressões do lucro e do marketing empresarial e individual estão ausentes, a Wikipédia surge como um modelo antineoliberal e anti-lucro individualista ou corporativo, o que, em grande medida, constitui a chave do sucesso no combate a fake news e a dinâmicas de desinformação imbuídas de um espírito de capitalismo informacional (Castells, 2007; Benkler, 2020). Apesar das várias críticas listadas - a ausência de pares credenciados, a ascensão do não especialista, a diluição do autor, a organização num modelo não hierárquico e caótico, a ideia de que os editores estão a jogar um RPG e o confronto com o modelo neoliberal de informação instalado - a Wikipédia apresenta, direta e indiretamente, linhas de fuga que contrariam os atuais poderes instalados pela hegemonia do conhecimento, apresentando ao mesmo tempo um modelo decalcado do científico e com sucesso no combate às interferências da desinformação.

Apresentar uma missão universal sem fins lucrativos, um ethos decalcado do cientista ainda que mais sociotécnico e menos preso a regras rígidas, um estado permanentemente aberto, uma postura não hierárquica e colaborativa e um conjunto de regras, normas e processos próprios que concretizam continuamente uma cultura própria, é uma espécie de concretização objetiva do projeto inicial de Tim Berners Lee, aquela visão utópica, iluminista e romântica inscrita na ideia de internet. Mesmo que hoje a internet seja o lugar das grandes empresas especializadas em captologia e produtoras de "computadores carismáticos" dirigidos à "arte de captar a atenção do utilizador, quer este queira ou não" (Patino, 2019, p. 47), a Wikipédia resiste há 20 anos com preceitos humanistas que funcionam contra apetites corporativistas inscritos em estratégias de desinformação e em dinâmicas de pós-verdade orientada.

A Wikipédia pode assim servir de exemplo para se aumentar a diversidade e a alfabetização digital (Scofield, 2021; Preto, 2021; Carvalho, 2021), inspirando meios de comunicação social de massas com o seu modelo colaborativo no próprio processo de construção informativo, em que notícias e reportagens online podem ficar em regime aberto, funcionando como verbetes informativos de base para edição e ampliação voluntária posterior, isto sem abdicar de regras e de vigilância profissional (Benjakob \& Harrison, 2020).

Aproveitar as regras e boas práticas do ecossistema wikipedista pode ser um caminho para se pensar num verdadeiro combate às estratégias de desinformação e de pósverdade, tanto de grupos minoritários como de maiorias corporativas capitalistas. Um maior relacionamento entre academia e Wikipédia pode também potenciar um maior crescimento de ambos os lados, auxiliando na tarefa de combate à desinformação e às hegemonias informacionais.

No caso da notícia e do relato jornalístico em aberto, a experiência de combate ao vandalismo na Wikipédia pode ser aplicada por qualquer empresa de comunicação

plataformas podem aprender sobre como confiar nas pessoas e como construir essa confiança no longo prazo" (Carvalho, 2021, §8). 
social que se abra ao modelo colaborativo de produção noticiosa - ainda que a base tenha que conter necessariamente maior verticalismo devido à propriedade privada presente nas empresas de comunicação social. Um regime semi-aberto, com bots e scripts antivandalismo na própria secção colaborativa, poderia evitar o fechamento das notícias e propiciar desenvolvimentos imprevisíveis desde que as questões de facto, balizadas por fontes externas credíveis, fossem continuamente apuradas (Braz \& Souza, 2014). A notícia poderia ganhar com esta boa prática uma maior perspetiva de work in progress, colaborativo e de escrutínio coletivo.

Deste modo, poderíamos ter, por um lado, uma filosofia do tipo wikipedismo jornalista enquanto proposta conceptual e, por outro, uma comunidade de jornalistas que usariam as boas práticas inscritas na ação wikipedista como modo de cumprir e fazer cumprir um ethos axiologicamente mais neutro. O wikipedismo aplicado ao jornalismo funcionaria como uma espinha dorsal deontológica, fortificada por um foco nos pilares básicos do jornalismo, e a comunidade de jornalistas, inspirada por um ethos wikipedista, estaria no "terreno", em regime semi-aberto, dinâmico e sob o continuum de notícias, a fazer cumprir os desígnios deontológicos na notícia.

\section{REFERÊNCIAS}

BENJAKOB, Omer e HARRISON, Stephen, 2020. From Anarchy to Wikiality, Glaring Bias to Good Cop: Press Coverage of Wikipedia's First Two Decades. Wikipedia @ 20. [em linha]. [Acesso em 05 janeiro 2021]. Disponível em:

https://wikipedia20.pubpub.org/pub/u1f6cq5i

BENKLER, Yochai, 2020. From Utopia to Practice and Back.Wikipedia @ 20. [em linha]. [Acesso em 05 janeiro 2021]. Disponível em:

https://wikipedia20.pubpub.org/pub/3wt2fy6i

BRAZ, Sandrine Cristina de Figueirêdo e SOUZA, Edivanio Duarte, 2014. Os desafios da confiabilidade da informação na Produção colaborativa de conteúdos: Análises na Wikipédia, a Enciclopédia Livre. Ciência da Informação em Revista [em linha],vol. 1, n³, p. 19-31. [Acesso em 07 janeiro 2021]. Disponível em:

https://www.seer.ufal.br/index.php/cir/article/view/1597

CARVALHO, Lucas, 2021. Wikipédia completa 20 anos com menos desinformação do que redes sociais. Portal Imprensa [em linha]. 18 de janeiro 2021. [Acesso em 07 janeiro 2021]. Disponível em:

https://portalimprensa.com.br/noticias/ultimas_noticias/84181/wikipedia+completa+2 o+anos+com+55+milhoes+de+artigos+e+menos+desinformacao+do+que+redes+soci ais

COSTA, Bernardo Esteves Gonçalves, 2014. As controvérsias da ciência na wikipédia em português: o caso do aquecimento global [em linha]. [Acesso em 07 janeiro 2021]. Rio de Janeiro: UFRJ. Disponível em: https://is.cos.ufrj.br/wpcontent/uploads/2015/11/BernardoEsteves-Tese-2014.pdf 
COSTA, Pedro Rodrigues, 2020a. Uma cartografia do ódio no Facebook: gatilhos, insultos e imitações. Comunicação Pública [em linha], vol. 15(29), p.01-28. [Acesso em 07 janeiro 2021]. Disponível em: https://journals.openedition.org/cp/11367

COSTA, Pedro Rodrigues, 2020b. A presença de arquétipos nos youtubers: modos e estratégias de influência. Revista Galáxia [em linha], vol.45, p.5-19. [Acesso em 08 janeiro 2021]. Disponível em: http://dx.doi.org/10.1590/1982-25532020347613

COSTA, Pedro Rodrigues, 2020c. Impactos da captologia. Problemáticas, desafios e algumas consequências do "dar vistas" ao ecrã em rede. Revista Sociologia Online [em linha], vol. 23, p.74-94. [Acesso em 08 janeiro 2021]. Disponível em: https://doi.org/10.30553/sociologiaonline.2020.23.4

COSTA, Pedro Rodrigues, 2020d. Eu sou tu. Tu és intelecto contingente. In J. P. Neves, P. R. Costa, P. de V. Mascarenhas, I. T. de Castro \& V. R. Salgado, 2020. Eu sou tu. Experiências ecocríticas [em linha], p.271-294. [Acesso em 08 janeiro 2021]. Braga: CECS. Disponível em:

http://www.lasics.uminho.pt/ojs/index.php/cecs_ebooks/article/view/3325

COSTA, Pedro Rodrigues, 2021a. A Wikipédia como veículo de conhecimento nos países de língua portuguesa. Communitas Think Tank [em linha]. CECS, Instituto de Ciências Sociais - Universidade do Minho: Braga. [Acesso em 19 janeiro 2021]. Disponível em: http://repositorium.sdum.uminho.pt/handle/1822/70150

COSTA, Pedro Rodrigues, 2021b. A verdade enquanto verificabilidade supervisionada: eis a receita da Wikipédia para o combate à desinformação. O Espectador [em linha]. 03 de maio 2021. [Acesso em 19 maio 2021]. Disponível em: https://www.oespectador.pt/2021/05/03/a-verdade-enquanto-verificabilidadesupervisionada-eis-a-receita-da-wikipedia-para-o-combate-a-desinformacao/

CUMMINGS, Robert, 2020. The First Twenty Years of Teaching with Wikipedia: From Faculty Enemy to Faculty Enabler. Wikipedia @ 20 [em linha]. [Acesso em 19 janeiro 2021]. Disponível em: https://wikipedia20.pubpub.org/pub/oegczf8e

DONDIO, Pierpaolo, BARRETT, Stephen, WEBER, Stefan e SEIGNEUR, Jean Marc, 2006. Extracting Trust from Domain Analysis: A Case Study on the Wikipedia Project. In: Yang L.T., Jin H., Ma J., Ungerer T. (eds). Autonomic and Trusted Computing. Lecture Notes in Computer Science [em linha], vol 4158. Springer, Berlin, Heidelberg. [Acesso em 19 janeiro 2021]. Disponível em: https://doi.org/10.1007/11839569_35

FONSECA, Ailton Siqueira de Souza e Braz, Emanuel Pereira, 1997. Considerações a respeito da neutralidade axiológica em Max Weber. Revista Expressão da Universidade Estadual do Rio Grande do Norte, vol.1, n.1. Mossoró: URRN.

GILES, Jim, 2005. Internet encyclopaedias go head to head. Nature [em linha], vol. 438, p.900-901. [Acesso em 19 janeiro 2021]. Disponível em:

https://www.nature.com/articles/438900a 
GRAYLING, Anthony Clifford, 2020. Uma história da filosofia. Lisboa: edições 70.

GREENSTEIN, Shane e ZHU, Feng, 2018. Do Experts or Crowd-Based Models Produce More Bias? Evidence from Encyclopedia Britannica and Wikipedia. MIS Quarterly [em linha], vol.42, n³, p.945-959. [Acesso em 19 janeiro 2021]. Disponível em: https://dash.harvard.edu/handle/1/41946110

HILL, Benjamin Mako, e SHAW, Aaron, 2020. The Most Important Laboratory for Social Scientific and Computing Research in History.Wikipedia @20 [em linha]. [Acesso em 19 janeiro 2021]. Disponível em: https://wikipedia20.pubpub.org/pub/fgas2h4l

JAMES, Richard, 2016. WikiProject Medicine: Creating Credibility in Consumer Health. Journal of Hospital Librarianship [em linha], vol. 16, n.4, p.344-351. [Acesso em 19 janeiro 2021]. Disponível em: https://www.tandfonline.com/doi/abs/10.1080/15323269.2016.1221284

JASCHIK, Scott, 2007. A stand against Wikipedia. Inside Higher Ed [em linha]. 26 de janeiro 2007. [Acesso em 19 janeiro 2021]. Disponível em: https://www.insidehighered.com/news/2007/01/26/stand-against-wikipedia

JEMIELNIAK, Dariusz, 2020. Wikipedia as a Role-Playing Game, or Why Some Academics Do Not Like Wikipedia.Wikipedia @ 20 [em linha]. [Acesso em 22 janeiro 2021]. Disponível em: https://wikipediazo.pubpub.org/pub/5fbicj2z

KIOUSIS, Spiro, 2001. Public Trust or Mistrust? Perceptions of Media Credibility in the Information Age. Mass Communication \& Society [em linha], vol. 4, nº4, p.381-403. [Acesso em 22 janeiro 2021]. Disponível em: https://www.tandfonline.com/doi/abs/10.1207/S15327825MCS0404_4

LATOUR, Bruno, 2020. Por que a crítica perdeu a força? De questões de fato a questões de interesse. O que nos faz pensar - Cadernos do Departamento de Filosofia da PUC-Rio [em linha], vol.29, n46, p.173-204. [Acesso em 22 janeiro 2021]. Disponível em: https://doi.org/10.32334/oqnfp.2020n46a748

MARTINS, Moisés de Lemos, 2011. Crise no castelo da Cultura. Das estrelas para os ecrãs. Coimbra: Grácio Editores.

MATA, Sérgio, 2010. "O dever-ser é coisa do Diabo"? Sobre o problema da neutralidade axiológica em Marx Weber. Dimensões [em linha]. [Acesso em 22 janeiro 2021]. Disponível em: http://www.periodicos.ufes.br/dimensoes/article/view/2533/2029

MCHENRY, Ricky, 2004. The Faith-Based Encyclopedia. Tech Central Station [em linha]. 15 de novembro 2004. [Acesso em 22 janeiro 2021]. Disponível em: www.techcentralstation.com/111504A.html 
MERTON, Robert King, 1973. The Sociology of Science: Theoretical and Empirical Investigations. Chicago: University of Chicago Press.

MILLER, Nora, 2005. Wikipedia and the disappearing "author". ETC: A Review of General Semantics [em linha]. vol. 62, nº1, p.37-40. [Acesso em 22 janeiro 2021]. Disponível em: http://www.generalsemantics.org/wp-content/uploads/2011/04/etc-621-sample-issue.pdf

NUNBERG, Georg, 2007. A Wiki's as Good as a Nod. NPR Fresh Air commentary [em linha]. 06 de maio 2007. [Acesso em 26 janeiro 2021]. Disponível em: https://people.ischool.berkeley.edu/ nunberg/wikipedia.html

PADILHA, Isabella Maria Cavalcante, LIMA JÚNIOR, Mácio Paulo Amara e SANTOS, Magnólia Rejane Andrade, 2019. A democratização da divulgação científica através do Wikipédia. In XXI Congresso de Ciências da Comunicação na Região Nordeste, São Luís, de 30/05 a 01/06/2019. Disponível em: https://portalintercom.org.br/anais/nordeste2019/resumos/R67-1218-1.pdf

PEQUENINO, Karla, 2021. "Variantes da língua” são maior motivo de discórdia entre editores da Wikipédia em português. Público [em linha]. 10 de fevereiro 2021. [Acesso em 26 fevereiro 2021]. Disponível em: https://www.publico.pt/2021/02/10/tecnologia/noticia/variantes-lingua-sao-maiormotivo-discordia-editores-wikipedia-portugues-1950186

PESTANA, Filomena, 2018. A Wikipédia como recurso educacional aberto: um contributo para o Programa Wikipédia na Universidade. Universidade Aberta [em linha]. [Acesso em 26 fevereiro 2021]. Disponível em: https://repositorioaberto.uab.pt/handle/10400.2/7372

PERNIOLA, Mário, 1993. Do sentir. Lisboa: Presença.

PRETO, Mando, 2021. Mulheres são as que menos criam ou editam na Wikipédia em português. Minho Digital. 12 de fevereiro 2021. [em linha]. [Acesso em 26 fevereiro 2021]. Disponível em: https://minhodigital.com/news/mulheres-sao-que-menos-criam

QUEROL, Ricardo, 2016. As redes sociais são uma armadilha - Zygmunt Bauman. Revista Prosa Verso e Arte [em linha]. [Acesso em 26 fevereiro 2021]. Disponível em: https://www.revistaprosaversoearte.com/as-redes-sociais-sao-uma-armadilhazygmunt-bauman/

RABIN, Cláudio Goldberg, 2016. Como erros, boatos, mentiras e pegadinhas na Wikipédia afetam o mundo real. Motherboard [em linha]. 7 de julho 2016. [Acesso em 26 fevereiro 2021]. Disponível em: http://motherboard.vice.com/pt_br/read/comomentiras-na-wikipdia-afetam-o-mundo-real

REAGLE, Joseph, 2010. 'Be Nice': Wikipedia Norms for Supportive Communication. New Review of Hypermedia and Multimedia [em linha]. Vol. 16, no. 1-2, p.161-180. 
[Acesso em 26 fevereiro 2021]. Disponível em: https://www.tandfonline.com/doi/abs/10.1080/13614568.2010.498528

RIJSHOUWER, Emiel, 2019. Organizing Democracy: Power Concentration and SelfOrganization in the Evolution of Wikipedia. Rotterdam: Erasmus University Press.

SCOFIELD, Laura, 2021. Grupo se reúne para proteger a Wikipédia do negacionismo climático. Agência Pública [em linha]. 21 de janeiro de 2021. [Acesso em 26 fevereiro 2021]. Disponível em: https://apublica.org/2021/01/grupo-se-reune-para-proteger-awikipedia-do-negacionismo-climatico/

SUNDIN, Olof, 2011. Janitors of knowledge: constructing knowledge in the everyday life of Wikipedia editors. Journal of Documentation [em linha]. vol. 67 No. 5, pp. 840862. [Acesso em 26 fevereiro 2021]. Disponível em:

https://doi.org/10.1108/00220411111164709

TKACZ, Nathaniel, 2015. Wikipedia and the Politics of Openness. Chicago: University of Chicago Press.

TARDE, Gabriel, 1978. As leis da imitação. Porto: Rés Editora.

VIANA, Nildo, 2007. Os valores na sociedade moderna. Brasília: Thesaurus.

VOGT, Carlos, 2003. A espiral da cultura científica. Revista Eletrônica com Ciência [em linha], 45, s.p. [Acesso em 26 fevereiro 2021]. Disponível em:

http://www.comciencia.br/dossies-1-72/reportagens/cultura/cultura01.shtml

WEBER, Max, 2006. A “objetividade” do conhecimento nas ciências sociais. São Paulo: Ática. 